\title{
PEDF decreases cardiomyocyte edema during oxygen-glucose deprivation and recovery via inhibiting lactate accumulation and expression of AQP1
}

\author{
BING HUANG ${ }^{1,2^{*}}$, HAORAN MIAO $^{1 *}$, YANLIANG YUAN ${ }^{1}$, FAN QIU $^{1}$, XIUCHENG LIU $^{1}$, ZHIWEI LIU $^{3}$, \\ HU ZHANG $^{1}$, QIXIANG ZHAO ${ }^{1}$, MENG WANG $^{3}$, HONGYAN DONG $^{3}$ and ZHONGMING ZHANG ${ }^{1}$
}

${ }^{1}$ Department of Thoracic Cardiovascular Surgery, Affiliated Hospital of Xuzhou Medical University, Xuzhou, Jiangsu 221006;

${ }^{2}$ Department of Thoracic Cardiovascular Surgery, Affiliated Huaihai Hospital of Xuzhou Medical University;

${ }^{3}$ Morphological Research Experiment Center, Xuzhou Medical University, Xuzhou, Jiangsu 221004, P.R. China

Received August 31, 2018; Accepted February 28, 2019

DOI: $10.3892 / \mathrm{ijmm} .2019 .4132$

\begin{abstract}
Myocardial edema is divided into cellular edema and interstitial edema; however, the dynamic change of cardiomyocyte edema has not been described in detail. Pigment epithelium-derived factor (PEDF) is known for its protective effects on ischemic cardiomyocytes; however, the association between PEDF and cardiomyocyte edema remains to be fully elucidated. In the present study, rat neonatal left ventricular cardiomyocytes were isolated and treated with oxygen-glucose deprivation (OGD) and recovery. During OGD and recovery, the cardiomyocytes exhibited significant edema following $30 \mathrm{~min}$ of OGD (OGD $30 \mathrm{~min}$ ) and OGD $30 \mathrm{~min}$ with recovery for $6 \mathrm{~h}$. PEDF significantly decreased the lactate content and extracellular acidification rate of the OGD-treated cardiomyocytes, thereby reducing cellular osmotic gradients and preventing the occurrence of cell edema. In addition, the glycolytic agonist, fructose-1, 6-diphosphate, eliminated the effect of PEDF on inhibiting edema in the OGD-treated cardiomyocytes. Furthermore, PEDF reduced the protein and mRNA expression of aquaporin 1 (AQP1), and thus downregulated cardiomyocyte edema during the OGD/recovery period. The addition
\end{abstract}

Correspondence to: Professor Zhongming Zhang, Department of Thoracic Cardiovascular Surgery, Affiliated Hospital of Xuzhou Medical University, 99 Huaihai Road, Xuzhou, Jiangsu 221006, P.R. China

E-mail: zhang_zhongming@xzhmu.edu.cn

Professor Hongyan Dong, Morphological Research Experiment Center, Xuzhou Medical University, 209 Tongshan Road, Xuzhou, Jiangsu 221004, P.R. China

E-mail: dhy@xzhmu.edu.cn

${ }^{*}$ Contributed equally

Key words: pigment epithelium-derived factor, oxygen-glucose deprivation, recovery, edema aquaporin of AQP1 agonist, arginine vasopressin, inhibited the inhibitory effect of PEDF on cardiomyocyte edema during OGD/recovery. In conclusion, the present study revealed a novel mechanism for the regulation of cardiomyocyte edema by PEDF involving lactate levels and the expression of AQP1 during OGD/recovery. The reduction of lactate content during OGD was associated with a decrease in the protein level of AQP1 during OGD/recovery; therefore, PEDF decreased cardiomyocyte edema and cellular apoptosis, prolonging the viability of the cells.

\section{Introduction}

Myocardial edema occurs in various myocardial pathologies, particularly in ischemia and reperfusion, and contributes to cell dysfunction and death (1). Edema is one of the consequences of a short period myocardial ischemia, which is reversible in the initial stage (2). Following myocardial reperfusion, due to abnormal fluid accumulation in cardiomyocytes and interstitial compartments, there is an marked edematous reaction in the myocardium, causing myocardial dysfunction and cell death $(3,4)$. Myocardial edema is divided into cellular edema and interstitial edema $(5,6)$, and its measurement is primarily based on the noninvasive evaluation of cardiac magnetic resonance imaging (7) and tissue water content (8). A number of studies have focused on global myocardial edema during ischemia-reperfusion (I/R). However, few studies have described the dynamic change in terms of cardiomyocyte edema.

It is well established that water movement across cell membranes is passive and is determined by osmotic gradients and membrane permeability to water. During systolic depolarization, $\mathrm{Na}^{+}$enters the cardiomyocyte due to the large voltage and concentration gradients, and repolarization is mainly achieved via $\mathrm{K}^{+}$efflux. Furthermore, the intracellular $\mathrm{Na}^{+}$concentration is dispersed by the effects of $\mathrm{Na}^{+}-\mathrm{K}^{+}$-ATPase (an $\mathrm{Na}^{+}$pump). Ionic homeostasis is an energy consuming process and any energy deficiency results in $\mathrm{Na}^{+}$overload and cell edema $(9,10)$. Furthermore, $\mathrm{Na}^{+}$concentration is also necessary for intracellular $\mathrm{pH}$ regulation. $\mathrm{H}^{+}$efflux is largely 
dependent on $\mathrm{Na}^{+}$influx via the $\mathrm{Na}^{+}-\mathrm{H}^{+}$exchanger (NHE) and $\mathrm{Na}^{+}-\mathrm{HCO}^{-}$transporter. Therefore, the accumulation of intracellular $\mathrm{H}^{+}$also causes $\mathrm{Na}^{+}$overload and induces changes in cell volume (11). During myocardial ischemia, due to energy insufficiency and glycolytic activation (lactate accumulation leads to a decrease in $\mathrm{pH}$ ), inactivation of the $\mathrm{Na}^{+}$pump and activation of the NHE results in $\mathrm{Na}^{+}$influx and leads to cardiomyocyte edema.

Aquaporins (AQPs) are a large membrane protein family, which usually oligomerize into tetramers, forming pores. These pores are permeable to water and serve a vital role in osmoregulation and water transport. AQPs have also been identified in the human cardiomyocyte membrane (12). The protein and mRNA expression levels of sarcolemmal AQP-4 in cardiomyocytes are enhanced during $I / R$, and this increase has been connected to enlarged infarct sizes (13). A decrease in the expression of AQP-4 in mouse brains downregulates the cell edema and necrosis induced by ischemia (14). Furthermore, the expression of AQP-1 has been identified in rat cardiomyocytes and appears to be associated with water movement (15). These results reveal that AQP may have a negative effect on I/R injury via regulating water transport and cardiomyocyte volume.

Pigment epithelium derived factor (PEDF) is an endogenous multifunctional protein which is commonly expressed in normal tissues (16), and serves protective roles in cardiomyocytes during oxygen-glucose deprivation (OGD) (17) and recovery (18). Our recent study suggested that PEDF protects cardiomyocytes undergoing OGD through reducing glycolytic activation and the level of ATP (19). These results motivated the hypothesis that PEDF may decrease cardiomyocyte edema during OGD by reducing lactate accumulation. However, the low level of ATP induced by PEDF may have a negative effect on cardiomyocyte edema during OGD. Furthermore, the association between PEDF and AQP in cardiomyocytes during OGD/recovery (I/R) remains to be fully elucidated. Therefore, the aims of the present study were to investigate the effect on PEDF on cardiomyocyte edema during I/R and to elaborate the underlying mechanisms of PEDF in the regulation of cardiomyocyte edema.

\section{Materials and methods}

Reagents. Cleaved caspase-3 antibody (cat. no. 9664, 1:1,000) was purchased from Cell Signaling Technology, Inc. (Danvers, MA, USA). Antibodies targeting protein kinase receptor-interacting protein 3 (RIP3, cat. no. 17563-1-AP, 1:1,000), AQP1 (cat. no. 20333-1-AP, 1:1,000), AQP4 (cat. no. 16473-1-AP, 1:1,000) and $\beta$-tubulin (cat. no. 66240-1-lg, 1:5,000) were purchased from ProteinTech Group, Inc. (Rosemont, IL, USA). Antibody targeting $\alpha$-sarcomeric actin ( $\alpha$-SCA, cat. no. SAB4200689, 1:500) was purchased from Sigma-Aldrich (Merck KGaA, Darmstadt, Germany). ATP disodium salt hydrate (cat. no. A1852), $\mathrm{Na}^{+}$-binding benzofuran isophthalate (SBFI, cat. no. 129423-53-6), the Lactate Assay kit II (cat. no. MAK065) and bromodeoxyuridine (BrdU; cat. no. B5002, $0.1 \mathrm{mM}$ ) were purchased from Sigma-Aldrich; Merck KGaA). Calcein AM (UltraPure grade, AAT bioquest 22003) was obtained from Shanghai Yubo Biological Technology Co., Ltd. (Shanghai, China).
Fructose-1, 6-diphosphate (FDP, 20 mM, cat. no. 81028-91-3) was obtained from Shanghai Guangrui Biological Technology Co., Ltd. (Shanghai, China). Arginine vasopressin (AVP; $0.1 \mathrm{nM}$; cat. no. 113-79-1) was purchased from Hangzhou Jinqi Biotechnology Co., Ltd. (Hangzhou, China). The Sodium Potassium ATPase Activity kit (cat. no. QS1700) was obtained from Shanghai Cablebridge Biotechnology Co., Ltd. (Shanghai, China).

PEDF protein preparation. Recombinant rat PEDF (GenBank ${ }^{\mathrm{TM}}$ accession no. NM_177927) was synthesized by Cusabio Biotech, Co., Ltd. (Wuhan, China) as described previously (20). Our previous studies demonstrated that $10 \mathrm{nmol} / \mathrm{l}$ is the optimal PEDF concentration for cardiomyocyte protection (21).

Lentivirus (LVs) and plasmid preparation. Recombinant lentivirus was prepared as described previously (22). The PEDF overexpression plasmid was constructed and packaged in 293 T cells (American Type Culture Collection, Manassas, VA, USA), and the concentrated titer of the viral suspension was $2 \times 10^{12} \mathrm{TU} / 1$.

Animals experiments. Adult male Sprague-Dawley (SD) rats (8-12 weeks old, 200-250 g) were supplied by the Experimental Animal Center of Xuzhou Medical University (Xuzhou, China) and housed in a controlled environment (humidity, $50-60 \%)$. A total of 3 rats were housed per cage and were maintained at room temperature under a $12 \mathrm{~h} \mathrm{light/dark} \mathrm{cycle;}$ rats were provided free access to food and water. The animal experiments performed in the present study conformed to the Guide for the Care and Use of Laboratory Animals published by the National Institutes of Health (Publication, 8th Edition, 2011, Bethesda, MD, USA) (23). The animal procedures were approved by the Xuzhou Medical University Committee on Animal Care. The I/R models were established as described previously (18). Intramyocardial gene delivery was performed 1 week prior to the I/R experiment in the rats. PEDF-LV $\left(2 \times 10^{7}\right.$ TU) with enhanced infection solution (Shanghai GeneChem Co., Ltd., Shanghai, China) was delivered into the infracted area of the myocardium. Sham-operated animals underwent an identical surgical procedure without left-anterior descending coronary artery ligation. For the rat I/R model, following 30 min of ischemic treatment, reperfusion was allowed for $2 \mathrm{~h}$ by releasing the ligatures. The animal models were randomly divided into eight groups as follows: i) Sham group, surgical procedure without artery ligation ( $\mathrm{n}=10)$; ii) Sham + PEDF-LV group, surgical procedure without artery ligation, PEDF-LV was transferred prior to surgery $(\mathrm{n}=10)$; iii) I group, $0.5 \mathrm{~h}$ ischemia $(\mathrm{n}=10)$; iv) ischemia + PEDF-LV group, $0.5 \mathrm{~h}$ ischemia, PEDF-LV was transferred prior to surgery $(\mathrm{n}=10)$; v) ischemia + vehicle group, $0.5 \mathrm{~h}$ ischemia, vehicle was transferred prior to surgery ( $\mathrm{n}=10)$; vi) I/R group, $0.5 \mathrm{~h}$ ischemia and $2 \mathrm{~h}$ reperfusion ( $\mathrm{n}=10)$; vii) I/R + PEDF-LV group, $0.5 \mathrm{~h}$ ischemia and $2 \mathrm{~h}$ reperfusion, PEDF-LV was transferred prior to surgery ( $\mathrm{n}=10)$; viii) $\mathrm{I} / \mathrm{R}+$ vehicle group, $0.5 \mathrm{~h}$ ischemia and $2 \mathrm{~h}$ reperfusion, vehicle was transferred prior to surgery $(\mathrm{n}=10)$.

Rat neonatal cardiomyocyte isolation and culture. Neonatal rat cardiomyocytes were isolated from neonatal male (1-3 days, 
5-7 g, $\mathrm{n}=700$ ) SD rats as previously described (24); rats were purchased from the Experimental Animal Centre of Xuzhou Medical University. The neonatal male SD rats were housed in the Experimental Animal Centre of Xuzhou Medical University and housed in a controlled environment (temperature, $20-25^{\circ} \mathrm{C}$; humidity, 50-60\%). The neonatal rats and their mother were housed one cage and were maintained at room temperature under a $12 \mathrm{~h}$ light/dark cycle. The neonatal rats were provided breast milk and the mother rat was provided free access to sterile food and water. The neonatal rats were anesthetized with sodium pentobarbital and sacrificed by decapitation. Their hearts were rapidly removed into dishes of ice, and the vessels and atria were discarded. The ventricles were then dissected and minced into $1 \mathrm{~mm}^{3}$ pieces, and washed in PBS. The minced tissue was digested in a PBS with $1 \mathrm{mg} / \mathrm{ml}$ trypsin, $1 \mathrm{mg} / \mathrm{ml}$ collagenase type II, and $0.2 \mathrm{mg} / \mathrm{ml}$ glucose for $5 \mathrm{~min}$ at $37^{\circ} \mathrm{C}$ and incubated with $0.1 \mathrm{mmol} / 1 \mathrm{BrdU}$ to selectively enrich for cardiomyocytes by inhibiting the growth of cardiac fibroblasts. The cardiomyocytes were then purified using the differential adhesion method. The cardiomyocytes were evaluated by indirect immunofluorescence staining with $\alpha$-SCA antibody. The isolated cardiomyocytes were cultured in Dulbecco's modified Eagle's medium (Gibco; Thermo Fisher Scientific, Inc.) with $4.5 \mathrm{~g} / 1$ glucose and $10 \%$ fetal bovine serum at $37^{\circ} \mathrm{C}$. OGD was completed by culturing the cardiomyocytes in a glucose-free DMEM (Gibco; Thermo Fisher Scientific, Inc.) without FBS and a tri-gas incubator (Heal Force, Shanghai, China) with $1 \% \quad \mathrm{O}_{2} / 5 \% \quad \mathrm{CO}_{2} / 94 \% \mathrm{~N}_{2}$ at $37^{\circ} \mathrm{C}$. OGD/R was performed as previously described (25). Following the OGD procedure, the medium was replaced with DMEM with $4.5 \mathrm{~g} / 1$ glucose, and then transferred into a humidified normoxic atmosphere at $37^{\circ} \mathrm{C}$. The cardiomyocytes were treated with or without $10 \mathrm{nM}$ PEDF $1 \mathrm{~h}$ prior to ischemia or reperfusion. The following experimental groups were included: Normal group, OGD group (control, OGD $0.5 \mathrm{~h}), \mathrm{OGD}+\mathrm{PEDF}$ group, OGD/R group (control, OGD $0.5 \mathrm{~h}$ and recovery $6 \mathrm{~h}), \mathrm{OGD} / \mathrm{R}+\mathrm{PEDF}$ group.

Cell volume measurements. Cell volumes were measured by confocal laser scanning microscopy (Olympus Corporation, Tokyo, Japan). Firstly, the cardiomyocytes were stained with calcein AM $(2 \mu \mathrm{M})$ to stain the cellular cytosol. The cells were then cultured with pre-hypoxic glucose deprivation medium, maintained in an incubator containing $1 \% \mathrm{O}_{2} / 5 \% \mathrm{CO}_{2} / 94 \% \mathrm{~N}_{2}$ at $37^{\circ} \mathrm{C}$ for $15 \mathrm{~min}$. Mineral oil was added to the upper layer of the medium to prevent oxygen in the air from contacting the medium, to ensure that the cardiomyocytes were always in an anoxic state (26). Each culture plate with stained cardiomyocytes was placed on an inverted microscope. Furthermore, a single rod-shaped viable cardiomyocyte from each plate was selected and then scanned using an Argon beam (488 nm). Using ImagePro Plus 6.0 software (Media Cybernetics, Inc., Rockville, MD, USA) to calculate the area of each layer of the cell, the sum of the area of each layer of the cell multiplied by a plane distance of $3 \mu \mathrm{m}$ was equal to the capacity of the cell.

Cell viability assessment. The rat primary cardiomyocytes ( $1 \times 10^{4}$ per well) were seeded into wells of a 96 -well plate (Corning, New York, USA). The cell viability was assessed using a CCK-8 kit (Dojindo Molecular Technologies, Inc., Tokyo, Japan). The absorbance at $450 \mathrm{~nm}$ was measured using a microplate reader (BioTek Synergy2, Instruments, Inc., Winooski, VT, USA). The mean optical density (OD) value from at least three parallel groups was used to calculate the cell viability.

Protein extraction. The rat heart tissue proteins were extracted from the left ventricular myocardium using a lysis buffer (100 mmol/1 Tris-HCl, 4\% SDS, 20\% glycerine, $200 \mathrm{mmol} / \mathrm{l}$ DTT, phosphatase and protease inhibitors, $\mathrm{pH}$ 6.8). The cardiomyocytes were lysed using the Cell Total Protein Extraction kit (Sangon Biotech, Shanghai, China) for whole cell lysates. The proteins were extracted using the Nuclear and Cytoplasmic Protein Extraction kit (Beyotime Institute of Biotechnology, Shanghai, China) for nuclear and cytoplasmic lysates according to the manufacturer's protocol. The protein concentrations were measured using a bicinchoninic acid assay.

Western blotting. For western blotting analysis, the cells were solubilized in lysis buffer $(100 \mathrm{mmol} / \mathrm{l}$ Tris-Hcl, 4\% SDS, $20 \%$ glycerine, $200 \mathrm{mmol} / 1 \mathrm{DTT}$, phosphatase and protease inhibitors, $\mathrm{pH}$ 6.8). Protein concentration from the supernatant was determined using a BCA protein assay kit (Pierce; Thermo Fisher Scientific, Inc.). Total cellular protein was denatured by boiling for $10 \mathrm{~min}$ with an equal volume of $2 \mathrm{X}$ Tris-glycine SDS buffer. A total of $50 \mathrm{ng}$ protein per lane was separated by $12 \%$ SDS-PAGE and transferred to nitrocellulose membranes (EMD Millipore, Billerica, MA, USA). Following blocking with 5\% non-fat milk/PBS-T for $3 \mathrm{~h}$ at room temperature, the membranes were incubated with primary antibodies overnight at $4^{\circ} \mathrm{C}$. Then, fluorescence-labeled secondary antibodies was added for $2 \mathrm{~h}$ at room temperature. Cleaved caspase-3 $(1: 1,000)$, RIP3 (1:1,000), AQP1(1:1,000), AQP4 (1:1,000) and $\beta$-tubulin $(1: 5,000)$ primary antibodies were used, followed by relative secondary antibodies (anti-rabbit IgG H+L DyLight ${ }^{\mathrm{TM}}$ 800 4X PEG 1:30,000; cat. no. 5151, and anti-mouse IgG H+L DyLight ${ }^{\mathrm{TM}} 680$ 1:15,000; cat. no. 5470, Cell Signaling Technology, Inc.) and images were captured using the Odyssey infrared imaging system (LI-COR Biosciences, Lincoln, NE, USA). Western blots were quantified using ImageJ software (v1.50; National Institutes of Health). The levels of protein were calculated by the ratio of relative protein/ $\beta$-tubulin.

Reverse transcription-quantitative polymerase chain reaction $(R T-q P C R)$ analysis. The total cardiomyocyte RNA was extracted using TRIzol reagent (Invitrogen; Thermo Fisher Scientific, Inc.) following the manufacturer's protocol. The RNA (1,000 nmol) was then subjected to reverse transcription with the Prime Script RT reagent kit and gDNA Eraser (Takara Biotechnology Co., Ltd., Dalian, China). PCR was conducted with a final volume of $20 \mu$ l containing $10 \mu \mathrm{l} 2 \mathrm{X}$ SYBR-Green PCR Master mix, $0.1 \mu \mathrm{M}$ of each primer and $100 \mu \mathrm{g}$ genomic DNA. The mixture was subjected to $\mathrm{qPCR}$ amplification $\left(95^{\circ} \mathrm{C}\right.$ for $\left.10 \mathrm{~min}\right), 45$ cycles $\left(95^{\circ} \mathrm{C}\right.$ for $10 \mathrm{sec}$, $60^{\circ} \mathrm{C}$ for $10 \mathrm{sec}, 72^{\circ} \mathrm{C}$ for $\left.20 \mathrm{sec}\right)$, and one cycle $\left(95^{\circ} \mathrm{C}\right.$ for $1 \mathrm{~min}, 65^{\circ} \mathrm{C}$ for $1 \mathrm{~min}$ and $97^{\circ} \mathrm{C}$ with continuous) and then cooled to $40^{\circ} \mathrm{C}$ for $30 \mathrm{sec}$ using a Roche Light Cycler 480 
(Roche Diagnostics GmbH, Mannheim, Germany). Gene expression was normalized to that of $18 \mathrm{~s}$ RNA. Gene expression was quantified using the $2^{-\Delta \Delta \mathrm{Cq}}$ method (27). The following primers, synthesized by GenScript (Piscataway, NJ, USA), were used: APQ1 forward, 5'-ACCTGCTGGCC ATTGACTAC-3' and reverse, 5'-CCAGGGCACTCCCAA TGAAT-3'; APQ4 forward, 5'-CCCCAGAAGACAGCACCT G-3' and reverse, 5'-GAGGGAGGTCCACACTTACAGC'; 18sRNA forward, 5'-CCTGGATACCGCAGCTAGGA-3' and reverse, 5'-GCGGCGCAATACGAATGCCCC-3'. The levels of mRNA were quantified through $18 \mathrm{~S}$ rRNA to normalize AQP-1 and AQP-4.

High performance liquid chromatography (HPLC) analysis. ATP levels was measured using an HPLC system (SIL-20A, Shimadzu Corporation, Kyoto, Japan) with detection at $205 \mathrm{~nm}$. Mobile phase A: $10 \mathrm{mmol} / 1 \mathrm{KH}_{2} \mathrm{PO}_{4}, 2.5 \%$ acetonitrile, $5.8 \mathrm{mmol} / 1$ tetrabutylammonium hydroxide, $\mathrm{pH}$ 6.0; Mobile phase $\mathrm{B}: 10 \mathrm{mmol} / 1 \mathrm{KH}_{2} \mathrm{PO}_{4}, 25 \%$ acetonitrile, $5.8 \mathrm{mmol} / 1$ tetrabutylammonium hydroxide, $\mathrm{pH} 5.5$; Reversed-phase $\mathrm{C} 185 \mu \mathrm{m}$ column $(250 \times 4.6 \mathrm{~mm})$ was used. The division of the peak area of samples by that of standards represented the ATP concentrations.

Extracellular acidification rate (ECAR) measurement. The ECAR was measured using a Seahorse XF96 extracellular flux analyzer (Seahorse Bioscience, North Billerica, MA, USA) which reflects the activity of glycolysis. The cardiomyocytes were seeded in 96-well assay plates at $8 \times 10^{3}$ cells/well and incubated at $37^{\circ} \mathrm{C}$ prior to analysis. ECAR was recorded immediately following the completion of OGD for the indicated time periods. The unit for ECAR was $\mathrm{mpH} / \mathrm{min}$.

Morphological assessment. The left ventricle was fixed in $10 \%$ paraformaldehyde and embedded in paraffin. Coronal sections (4- $\mu \mathrm{m}$ thick) of the left ventricle from the middle section were stained to determine the cross-sectional area (CSA) of cardiomyocytes as described previously $(28,29)$. A total of 50 cross-sections of cardiac muscle fibers were counted in at least 10 images of the left ventricle to assess the CSA. Each cell was traced individually, and its CSA was measured directly. The CSA measurements were performed on 10 rats, with 500 nuclei counted using ImagePro Plus software. Ultrathin sections were obtained using an EM UC7 (Leica Microsystems GmbH, Wetzlar, Germany). Mitochondrial CSA was determined using a Tecnai G2 T12 (FEI; Thermo Fisher Scientific, Inc.) transmission electron microscope to quantify the mitochondrial edema. For comparison of mitochondrial edema, electron microscope micrographs of thin sections were evaluated. In each of the 10 images of the left ventricle, $\sim 50$ mitochondria were confirmed.

Measurement of SBFI AM, lactic acid and $N A^{+}-K^{+}$-ATPase activity. The concentrations of SBFI AM, lactic acid and $\mathrm{NA}^{+}-\mathrm{K}^{+}$-ATPase activity were measured using the respective detection kits, according to the manufacturers' protocols.

Statistical analysis. Data in the present study are expressed as the mean \pm standard error of the mean. All statistical analyses were conducted using a SPSS 19.0 software (IBM Corp., Armonk, NY, USA). Data between two groups were compared using Student's $t$-test, and multiple comparisons used one-way analysis of variance and Student-Newman-Keuls test. $\mathrm{P}<0.05$ was considered to indicate a statistically significant difference.

\section{Results}

Cell edema increases in cardiomyocytes during $O G D$ and $O G D / R$. In order to examine the effects of ischemia and reperfusion on cardiomyocyte swelling, primary neonatal cardiomyocytes exposed to OGD for $30 \mathrm{~min}$ were isolated to mimic in vivo ischemia, and incubated in normal media with glucose and fetal bovine serum under normoxia to mimic in vivo recovery, thus simulating in vivo reperfusion. The volume of cardiomyocytes was measured by confocal tomography (Fig. 1A). The results indicated that, following OGD for $30 \mathrm{~min}$, the diameter of the cardiomyocytes increased from 8 to 10 layers, and after $6 \mathrm{~h}$, the number of layers increased further to 14 . The cell volume at each time point post-OGD/R was calculated by the aforementioned formula. The cardiomyocytes were significantly swollen within 15 min of OGD and continued to swell for $30 \mathrm{~min}$, following which the volume tended to stabilize within $2 \mathrm{~h}$. The maximum cell volume during the whole OGD/R process was $\sim 1$.4-fold higher than that of the normal cells (Fig. 1B). Within $30 \mathrm{~min}$ of recovery, the cell volume increased significantly and peaked at $6 \mathrm{~h}$; the volume of these cells was $\sim 1.75$-fold higher than that of normal cardiomyocytes (Fig. 1C). The cell volumes stabilized within $12 \mathrm{~h}$.

In addition, the effects of ischemia and reperfusion on cardiomyocyte edema were examined in vivo. The results revealed that the cardiomyocyte CSA in the infarct zone of the ischemia group was significantly higher than that in the sham group (Fig. 1D). Compared with the ischemia and sham groups, the cardiomyocyte CSA in the infarct zone of the I/R group was significantly increased. As shown in Fig. 1E, the mitochondria were swollen and the space between the organelles was increased in the ischemia group compared with the sham group; these changes were more prominent in the I/R group. These results suggested that OGD and OGD/R insults can lead to cardiomyocyte edema.

PEDF protects against OGD-induced cardiomyocyte edema and injury. To investigate the effect of PEDF on cardiomyocytes exposed OGD for $30 \mathrm{~min}$ (ischemia), the cell viability, and the levels of cleaved caspase-3 and RIP3 were evaluated. Cleaved caspase-3 and RIP3 are required for cell apoptosis (30) and necrosis (31), respectively. It was observed that PEDF was downregulated in the infarct region following AMI and I/R. Subsequently, a lentivirus carrying PEDF was transferred using intramyocardial injections to induce its overexpression in a rat AMI and I/R model (Fig. S1 A and $\mathrm{B})$. The results revealed that PEDF pre-treatment significantly alleviated OGD (ischemia)-induced cardiomyocyte edema (Fig. 2A). In addition, the level of cleaved caspase-3 was significantly increased and cell viability was decreased in the OGD group compared with the normal group; however, no significant change in the protein expression of RIP3 was observed (Fig. 2B and C). Furthermore, PEDF significantly alleviated the OGD-induced cardiomyocyte apoptosis and decrease of cell viability. In addition, PEDF pre-treatment 
A
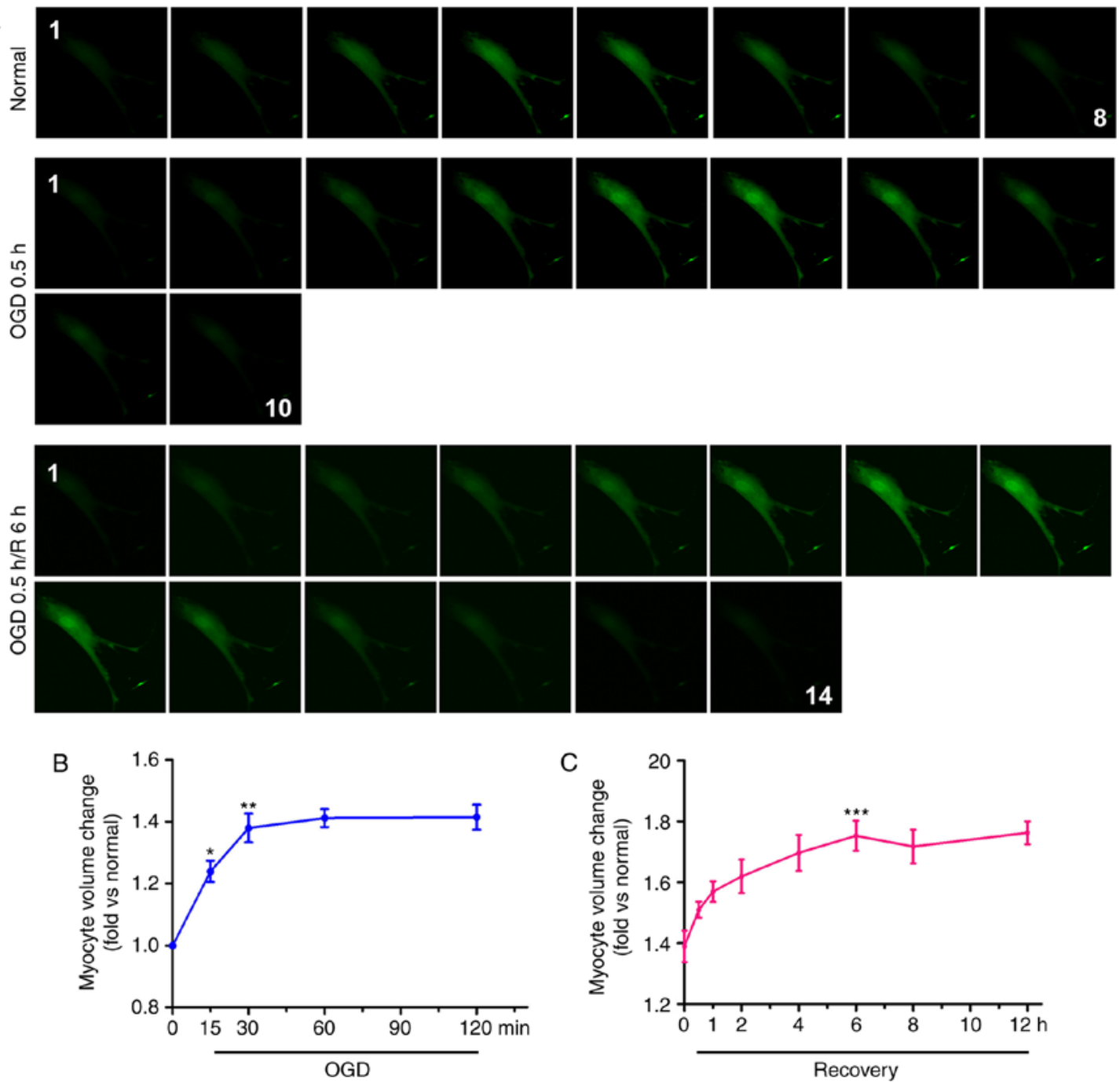

D
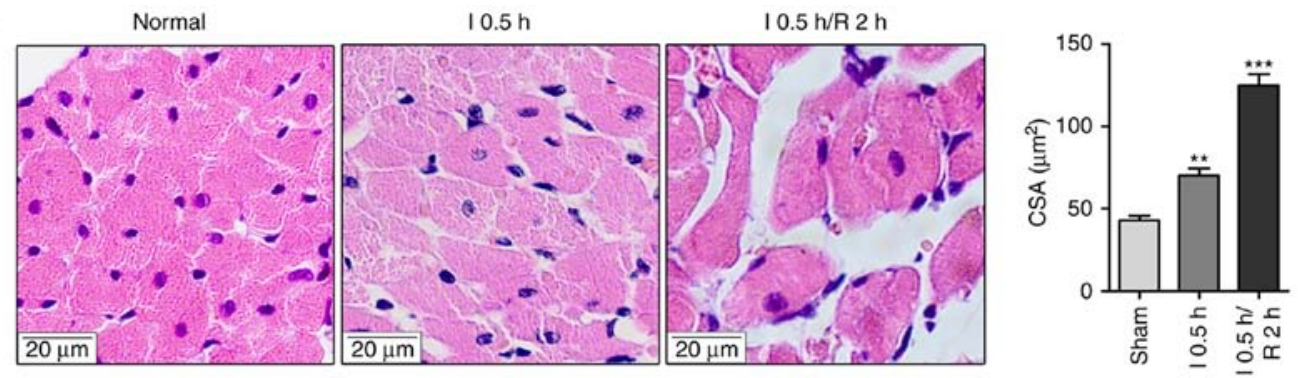

$\mathrm{E}$
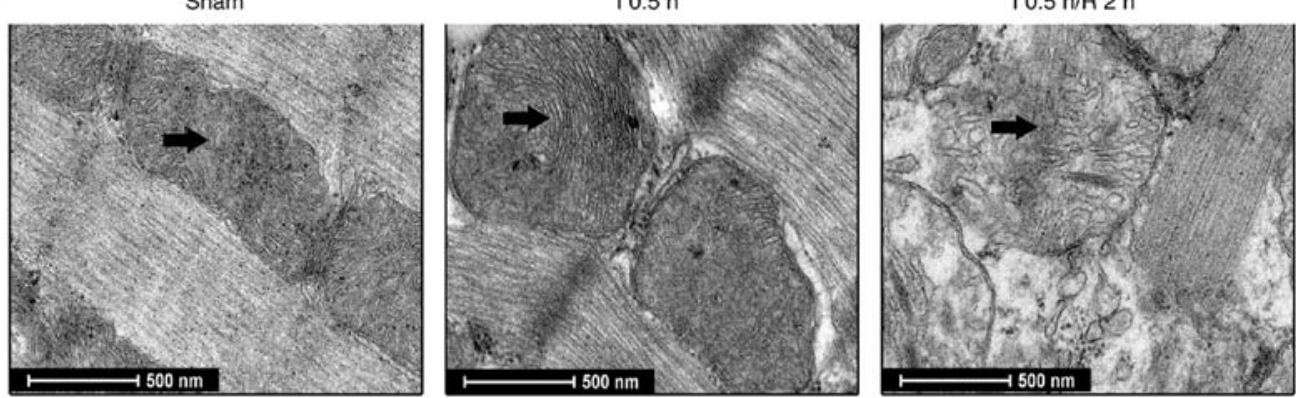

Figure 1. Cell edema increases in cardiomyocytes during OGD and OGD/R. (A) Calcein-AM was used to stain neonatal cardiomyocytes, and cell volume was measured with a confocal microscope by stack scanning (original magnification, $\mathrm{x} 400$ ). The time courses of cell volume changes in neonatal cardiomyocytes following (B) OGD and (C) 30 min of OGD/R $(n=6)$ are shown. ${ }^{*} \mathrm{P}<0.05$ and ${ }^{* *} \mathrm{P}<0.01$ and ${ }^{* * *} \mathrm{P}<0.001$, vs. relative normal group. (D) Hematoxylin and eosin-stained micrographs of myocardial sections from the left ventricle (original magnification, $\mathrm{x} 400$ ). The graph shows CSA values of the Sham, I $0.5 \mathrm{~h}$ and I $0.5 \mathrm{~h} / \mathrm{R} 2 \mathrm{~h}$ groups; the results are presented as the mean CSA of 50 random cells. The experiment was repeated six times. ${ }^{* *} \mathrm{P}<0.01$ and ${ }^{* * * *} \mathrm{P}<0.001$, vs. Sham group. (E) Transmission electron microscopy in cardiomyocytes. Arrows indicate mitochondria. (original magnification, x11,000). OGD, oxygen-glucose deprivation; OGD/R, OGD/recovery; I, ischemia; R, reperfusion; CSA, cross-sectional area. 

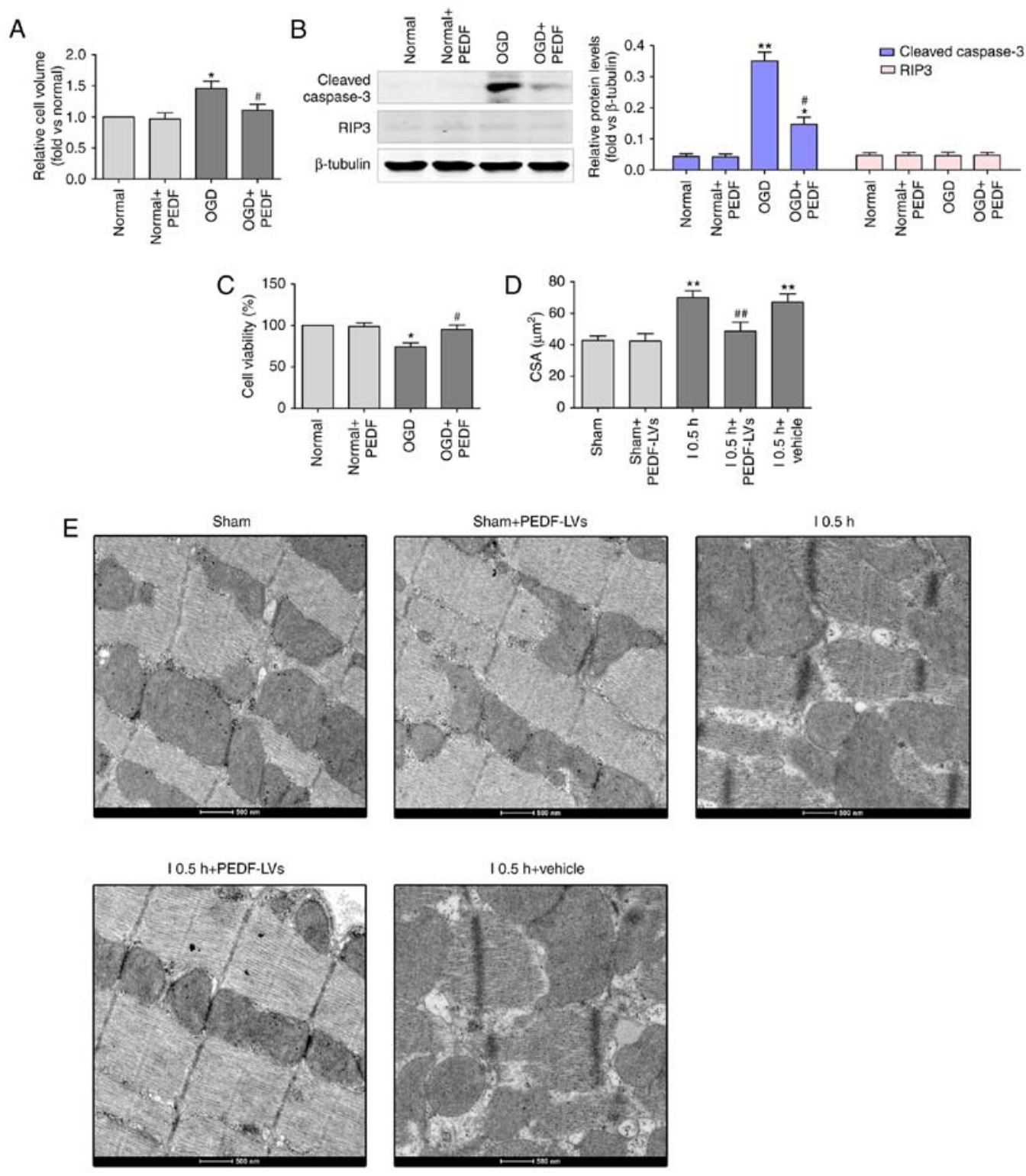

Figure 2. PEDF protects against OGD (ischemia)-induced cardiomyocyte edema and injury. (A) Cell volumes of 10 nmol/l PEDF-treated normal neonatal cardiomyocytes and neonatal cardiomyocytes following $30 \mathrm{~min}$ of OGD were measured by using confocal microscope stack scanning measurement (n=30). ${ }^{*} \mathrm{P}<0.05$, vs. relative normal group, ${ }^{*} \mathrm{P}<0.05$, vs. OGD group. (B) Protein levels of cleaved caspase-3 and RIP3 in PEDF-treated normal neonatal cardiomyocytes and neonatal cardiomyocytes following OGD were analyzed by western blotting $(n=6)$. (C) A Cell Counting kit- 8 assay was performed to assess cell viability in neonatal cardiomyocytes $(\mathrm{n}=6)$. ${ }^{*} \mathrm{P}<0.05$ and ${ }^{* *} \mathrm{P}<0.01$, vs. relative normal controls; ${ }^{*} \mathrm{P}<0.05$, vs. relative OGD controls. (D) Cardiomyocyte CSAs were measured following ischemia. Rats were divided into the Sham, Sham + PEDF-LVs, AMI, AMI + PEDF-LVs and AMI + vehicle groups (n=6). ${ }^{* *} \mathrm{P}<0.01$, vs. Sham group; ${ }^{\#} \mathrm{P}<0.05$ and ${ }^{\# /} \mathrm{P}<0.01$, vs. AMI group. (E) Transmission electron microscopy of cardiomyocytes (original magnification, $\mathrm{x} 11,000$ ). OGD, oxygen-glucose deprivation; PEDF, pigment epithelium derived factor; LV, lentivirus; RIP3, receptor-interacting protein 3; AMI, acute myocardial ischemia; CSA, cross-sectional area.

significantly alleviated OGD (ischemia)-induced cardiomyocyte edema in vitro and in vivo (Fig. 2D and E). These results demonstrated that PEDF has protective effects on cardiomyocytes undergoing OGD to inhibit cell edema and injury.

PEDF reduces the concentration of $\mathrm{Na}^{+}$and activation of glycolysis in cardiomyocytes undergoing $O G D$. As shown in Fig. $3 \mathrm{~A}, \mathrm{Na}^{+}$concentration was significantly increased in cardiomyocytes during OGD compared with that in the normal group, and was significantly reduced in the OGD + PEDF group. In addition, the level of ATP was decreased in the OGD + PEDF group compared with that in the OGD group (Fig. 3B).
However, no significant difference was identified in the activity of $\mathrm{Na}^{+}-\mathrm{K}^{+}$ATPase between the OGD + PEDF and normal groups (Fig. 3C). Lactic acid content and ECAR were significantly increased in cardiomyocytes during OGD compared with the normal group, and were significantly reduced in the OGD + PEDF group (Fig. 3D and E). No significant differences in the mRNA and protein expression levels of AQP1 were observed in the OGD and OGD + PEDF groups compared with the normal group (Fig. 3F and G). Notably, no mRNA or protein expression of AQP4 was detected in cardiomyocytes. These results demonstrated that PEDF treatment decreased the concentration of $\mathrm{Na}^{+}$and the activation of glycolysis in cardiomyocytes during OGD. 

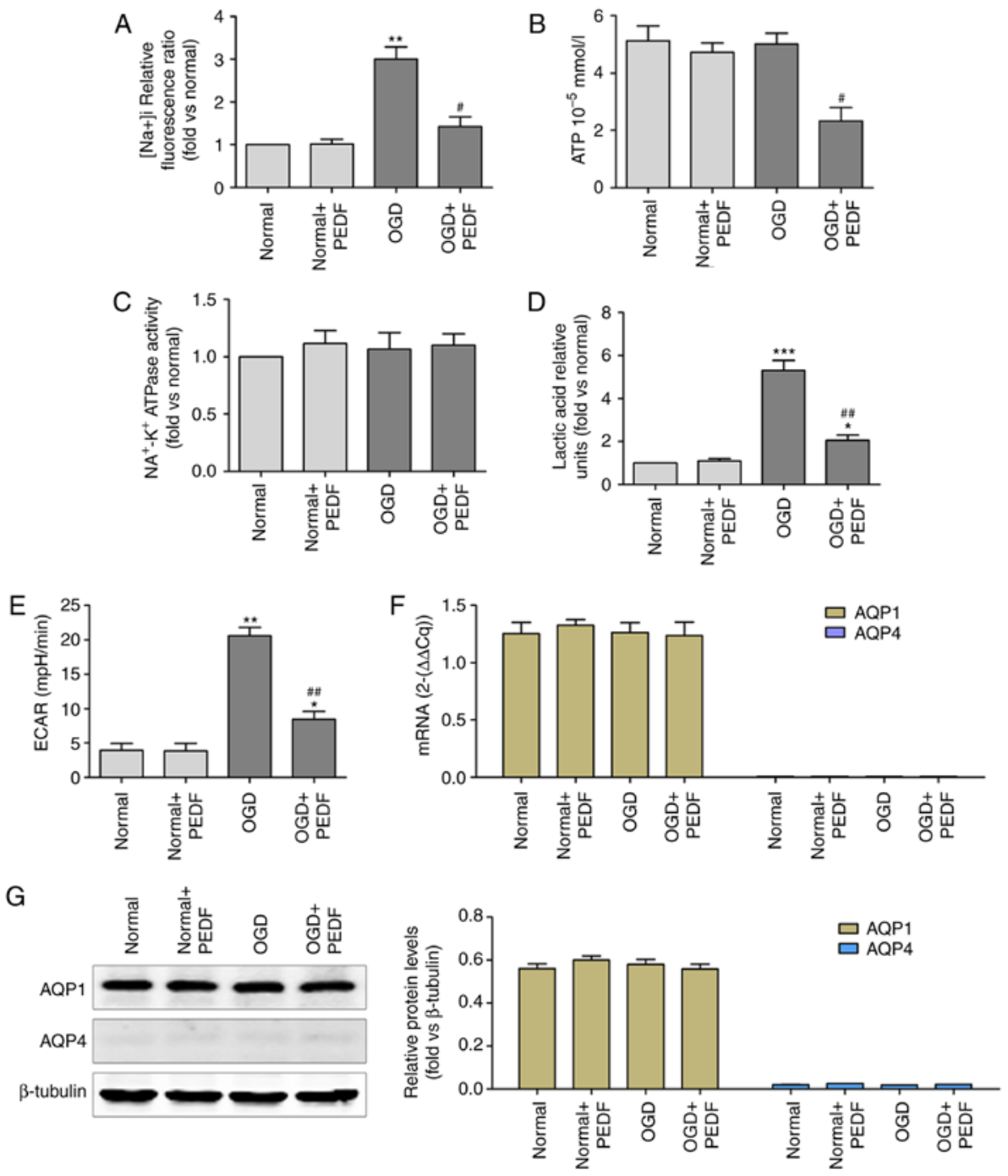

Figure 3. PEDF reduces $\mathrm{Na}^{+}$concentration and glycolytic activation in cardiomyocyte undergoing OGD. (A) $\mathrm{Na}^{+}$concentration, (B) ATP concentration, (C) $\mathrm{Na}^{+}-\mathrm{K}^{+}$ATPase activity, (D) lactic acid concentration, (E) extracellular acidification rate, and (F) mRNA and (G) protein expression levels of aquaporin were measured in neonatal cardiomyocytes. Cells were divided into the Normal, Normal + PEDF, OGD and OGD + PEDF groups $(n=6)$. ${ }^{*} \mathrm{P}<0.05$ and ${ }^{* * *} \mathrm{P}<0.01$ and ${ }^{* * *} \mathrm{P}<0.001$, vs. Normal group; ${ }^{\#} \mathrm{P}<0.05$ and ${ }^{\# \#} \mathrm{P}<0.01$, vs. OGD group. OGD, oxygen-glucose deprivation; PEDF, pigment epithelium derived factor; ECAR, extracellular acidification rate.

Effects of PEDF on OGD-induced cardiomyocyte edema and injury are associated with decreases in the activation of glycolysis. The $\mathrm{Na}^{+}$and lactic acid content were increased in the PEDF + FDP group compared with the PEDF group (Fig. 4A and B). Cardiomyocytes that underwent OGD were treated with PEDF and the glycolytic agonist, FDP, to increase ECAR, activating glycolysis (Fig. 4C). Furthermore, FDP significantly inhibited the positive effects on the cardiomyocytes exposed to OGD caused by PEDF (Fig. 4D and E), and inhibited the inhibitory effects of PEDF on cardiomyocyte edema (Fig. 4F). These results revealed that glycolytic activation inhibited the PEDF-induced inhibition of cardiomyocyte edema. Therefore, PEDF may inhibit OGD-induced cardiomyocyte edema by decreasing the activation of glycolysis.

PEDF inhibits cardiomyocyte edema and injury during $O G D / R$ $(I / R)$. As PEDF decreased OGD-induced cardiomyocyte edema, the present study investigated whether PEDF also reduced cardiomyocyte edema during OGD/R. The results revealed that the in vitro cell volume during $\mathrm{OGD} / \mathrm{R}(\mathrm{I} / \mathrm{R})$ was significantly increased compared with that in the OGD group (Fig. 5A). The protein expression levels of cleaved caspase-3 and RIP3 were increased, and cell viability was decreased in the $\mathrm{OGD} / \mathrm{R}$ group compared with the OGD group (Fig. 5B and C). In addition, the in vivo results demonstrated that the CSA, mitochondrial edema and the space between organelles during OGD/R were significantly increased compared with those in the OGD group (Fig. 5D and E). Importantly, PEDF treatment significantly inhibited cardiomyocyte edema during OGD/R, PEDF significantly inhibited apoptosis and necrosis, and increased cell viability in cardiomyocytes during $\mathrm{OGD} / \mathrm{R}$.

Effects of PEDF on OGD/R cardiomyocyte edema and injury are associated with a decrease of the expression of $A Q P 1$. The mechanism of PEDF that allows it to reduce OGD/R-induced cardiomyocyte edema was then investigated. Although the mechanism of PEDF-induced reductions in edema in cardiomyocytes undergoing OGD was demonstrated to be associated with a decrease of glycolytic activity, no significant difference in $\mathrm{Na}^{+}$concentration was identified between the 

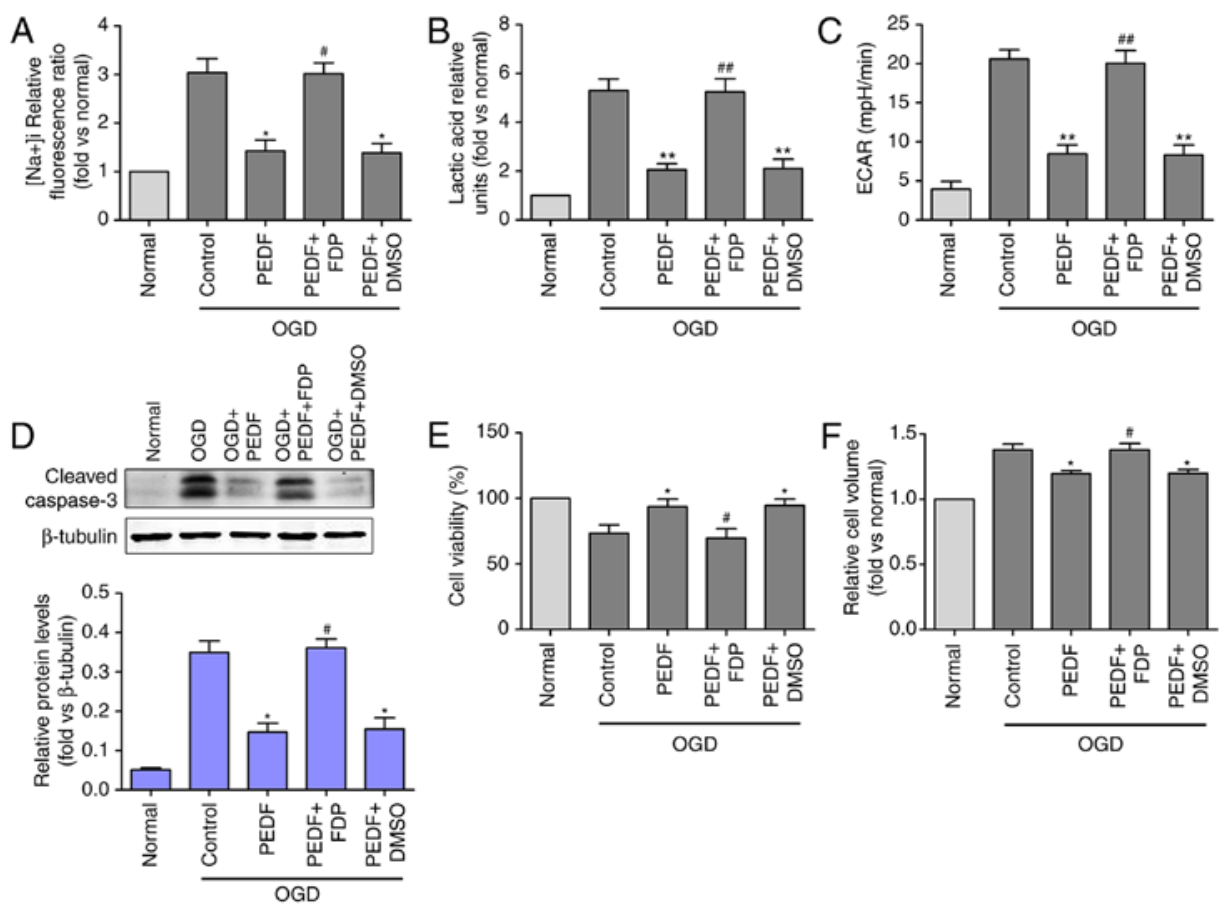

Figure 4. Effects of PEDF on OGD-induced cardiomyocyte edema and injury are associated with decreases in glycolytic activation. (A) Na ${ }^{+}$concentration, (B) lactic acid concentration, (C) extracellular acidification rate, (D) protein expression of cleaved caspase-3, and (E) cell viability and (F) cell volume were measured in neonatal cardiomyocytes. Cells were divided into the OGD, OGD + PEDF, OGD + PEDF + FDP, OGD + PEDF + DMSO groups ( $\mathrm{n}=6)$. ${ }^{*} \mathrm{P}<0.05$ and ${ }^{* *} \mathrm{P}<0.01$, vs. OGD group; ${ }^{*} \mathrm{P}<0.05$ and ${ }^{\# \#} \mathrm{P}<0.01$, vs. OGD + PEDF group. OGD, oxygen-glucose deprivation; PEDF, pigment epithelium derived factor; FDP, fructose-1, 6-diphosphate; RIP3, receptor-interacting protein 3; ECAR, extracellular acidification rate.
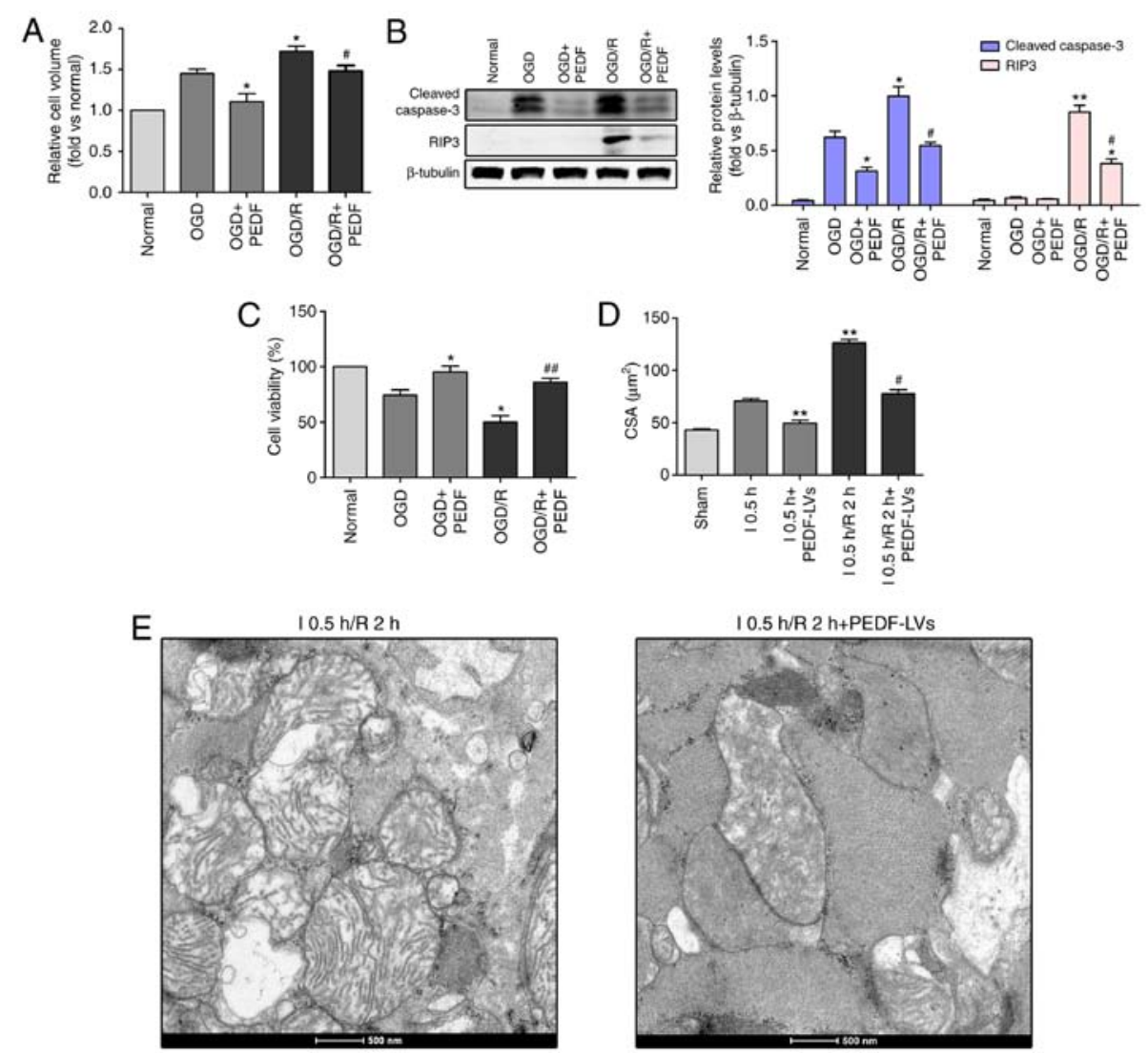

Figure 5. PEDF inhibits cardiomyocyte edema and injury in OGD/R. (A) Cell volume, (B) protein expression of cleaved caspase-3 and RIP3, and (C) cell viability were measured in neonatal cardiomyocytes. Cells were divided into the OGD, OGD + PEDF, OGD/R and OGD/R + PEDF groups ( $\mathrm{n}=6$ ). ${ }^{\mathrm{P}}<0.05$ and ${ }^{* *} \mathrm{P}<0.01$, vs. OGD control group; ${ }^{*} \mathrm{P}<0.05$ and ${ }^{\# \#} \mathrm{P}<0.01$, vs. OGD/R control group. (D) CSAs in the I $0.5 \mathrm{~h}, \mathrm{I} 0.5 \mathrm{~h}+\mathrm{PEDF}-\mathrm{LV}$ s, I $0.5 \mathrm{~h} / \mathrm{R} 2 \mathrm{~h}$ and I $0.5 \mathrm{~h} / \mathrm{R} 2 \mathrm{~h}+$ PEDF-LVs groups; the results are presented as the mean CSA of 50 random cells $(\mathrm{n}=6){ }^{*}{ }^{* *} \mathrm{P}<0.01$, vs. I group; ${ }^{*} \mathrm{P}<0.05$, vs. I $0.5 \mathrm{~h} / \mathrm{R} 2 \mathrm{~h}$ group. (E) Transmission electron microscopy of cardiomyocytes (original magnification, x11,000). OGD, oxygen-glucose deprivation; I, ischemia; R, reperfusion; PEDF, pigment epithelium derived factor; CSA, cross-sectional area; LV, lentivirus; RIP3, receptor-interacting protein 3. 

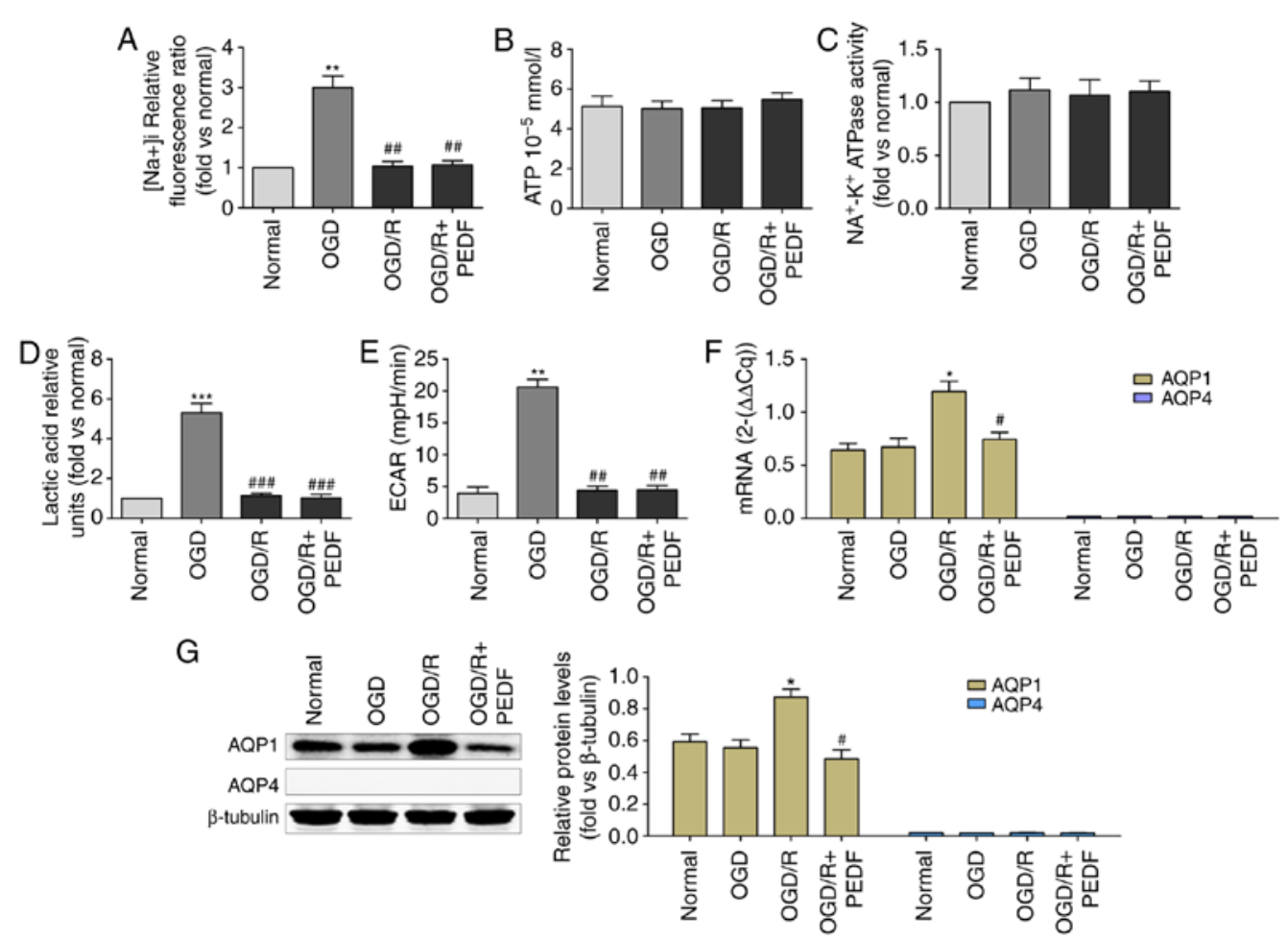

Figure 6. PEDF decreases the expression of AQP1 in cardiomyocytes during OGD/R. (A) $\mathrm{Na}^{+}$concentration, (B) ATP concentration, (C) Na ${ }^{+}-\mathrm{K}^{+}$ATPase activity, (D) lactic acid concentration, (E) extracellular acidification rate, and (F) mRNA and (G) protein expression of AQP1 were measured in neonatal cardiomyocytes. Cells were divided into the Normal, OGD, OGD/R and OGD/R + PEDF groups $(\mathrm{n}=6)$. ${ }^{*} \mathrm{P}<0.05$ and ${ }^{* *} \mathrm{P}<0.01$ and ${ }^{* * *} \mathrm{P}<0.001$, vs. Normal group; ${ }^{\#} \mathrm{P}<0.05$ and ${ }^{\# \#} \mathrm{P}<0.01$, vs. OGD/R group. OGD, oxygen-glucose deprivation; I, ischemia; R, reperfusion; PEDF, pigment epithelium derived factor; $\mathrm{AQP}$, aquaporin; ECAR, extracellular acidification rate.

OGD/R and OGD/R + PEDF groups (Fig. 6A). No significant differences in the ATP level and $\mathrm{Na}^{+}-\mathrm{k}^{+}$ATPase activity were identified between the normal, OGD, OGD/R, and OGD/R + PEDF groups (Fig. 6B and C). Additionally, no significant differences in lactic acid content or ECAR were identified between the OGD/R and OGD/R + PEDF groups (Fig. 6D and E). Notably, OGD/R significantly increased the mRNA and protein expression levels of AQP1 in cardiomyocytes, whereas the expression of AQP1 decreased significantly following PEDF treatment (Fig. 6F and G). These results suggested that PEDF decreases the expression of AQP1, rather than glycolytic activity, in cardiomyocytes during OGD/R.

Treatment with the AQP1 agonist AVP significantly alleviated the inhibited expression of AQP1 induced by PEDF (Fig. 7A-C). AVP treatment also eliminated PEDF-induced protection against apoptosis and necrosis, which prolonged cell viability in cardiomyocytes during OGD/R (Fig. 7D and E). Notably, OGD/R-induced cardiomyocyte edema was significantly increased in the PEDF + AVP group compared with that in the PEDF group (Fig. 7F). These results demonstrated that $\mathrm{PEDF}$ relieves $\mathrm{OGD} / \mathrm{R}$-induced cardiomyocyte edema via inhibiting the mRNA and protein expression of AQP1.

\section{Discussion}

To the best of our knowledge, the present study is the first to demonstrate that PEDF reduces OGD-induced cardiomyocyte edema through decreasing lactate accumulation, and inhibits the expression of AQP1 during the recovery period to prevent further cell edema. In the present study, cardiomyocytes exhibited significant edema following $30 \mathrm{~min}$ of OGD. Although the edema of the cardiomyocytes was aggravated further following a longer period of hypoxia, the changes were not significant. In addition, although the present study did not examine changes in the size of cellular edema in the myocardium during the I/R period, significant cardiomyocyte edema following $30 \mathrm{~min}$ of ischemia and $30 \mathrm{~min}$ of ischemia/2 h of reperfusion were observed. PEDF inhibited OGD-induced cardiomyocyte edema in vitro and ex vivo.

It is noteworthy that PEDF reduced the ATP level in cardiomyocytes during OGD. However, $\mathrm{Na}^{+}$pump activation was not inhibited in the PEDF group compared with that in the OGD group, suggesting that the remaining ATP was sufficient to maintain $\mathrm{Na}^{+}$pump functionality and cell activity. The lactate content and ECAR in PEDF-treated cardiomyocytes undergoing OGD was significantly decreased compared with those in the OGD group, indicating that PEDF inhibited $\mathrm{H}^{+}$levels in cardiomyocytes undergoing OGD. Inhibition of the activity of NHE prevented $\mathrm{Na}^{+}$influx, thereby reducing cellular osmotic gradients and preventing the occurrence of OGD-induced cardiomyocyte edema. Furthermore, no significant differences in the $\mathrm{Na}^{+}$pump, activity of NHE or lactate content were identified between the OGD/R + PEDF and OGD + PEDF groups, which indicated that PEDF was not able to alleviate cardiomyocyte edema during the recovery period in terms of the further inhibition of lactate accumulation.

Notably, no protein expression of AQP4 was detected in rat cardiomyocytes, however, AQP4 mRNA was expressed. 
A

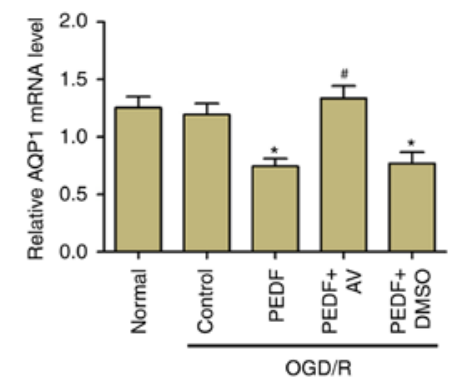

B

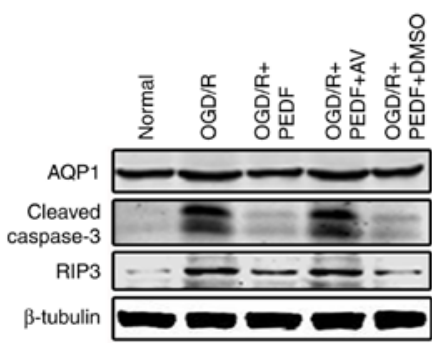

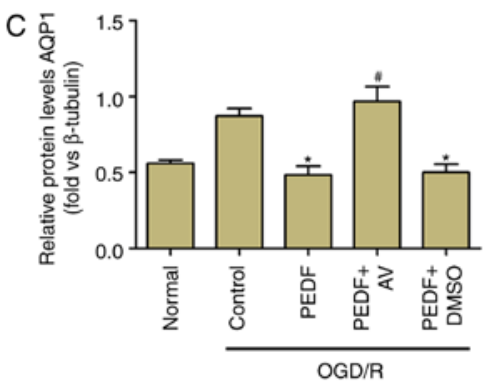

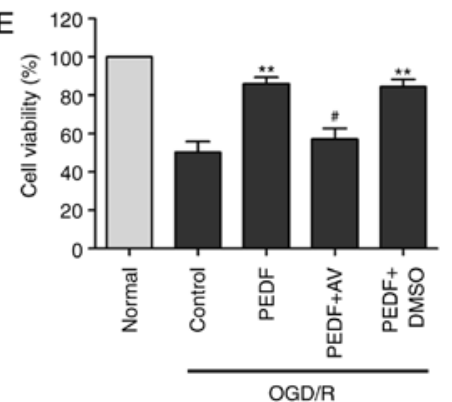

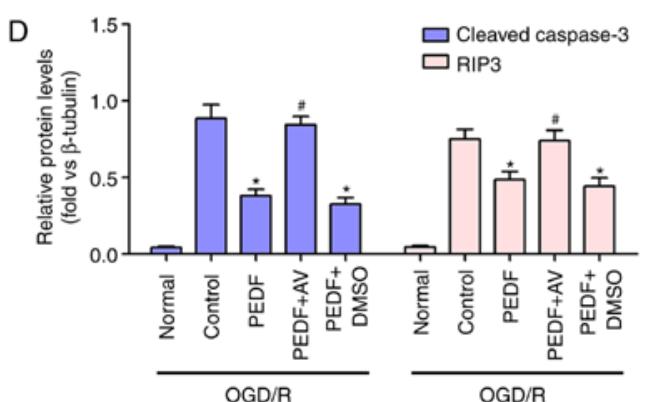

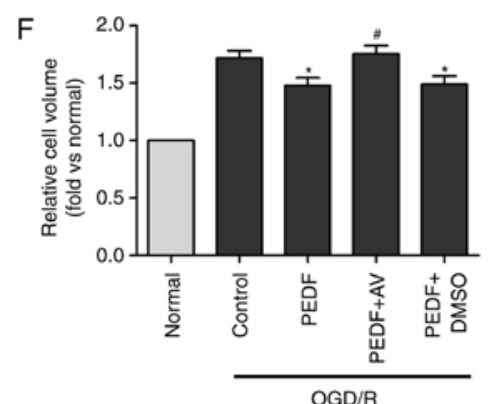

Figure 7. Reductions in cardiomyocyte edema and damage induced by PEDF during OGD/R are associated with inhibition of the expression of AQP1. (A) mRNA and (B) protein expression levels of AQP1, protein expression of (C) cleaved caspase-3 and (D) RIP3, and (E) cell viability and (F) cell volume were measured in neonatal cardiomyocytes. Cells were divided into the OGD/R, OGD/R + PEDF, OGD/R + PEDF + AV and OGD/R + PEDF + DMSO groups ( $\mathrm{n}=6) .{ }^{*} \mathrm{P}<0.05$ and ${ }^{* *} \mathrm{P}<0.01$, vs. OGD/R group; ${ }^{*} \mathrm{P}<0.05$, vs. OGD/R + PEDF group. OGD, oxygen-glucose deprivation; I, ischemia; R, reperfusion; PEDF, pigment epithelium derived factor; AQP1, aquaporin 1; RIP3, receptor-interacting protein 3; AVP, arginine vasopressin.

These data are consistent with that of previous studies $(12,32)$ and demonstrated that AQP4 is not involved in the occurrence of cellular edema in rat cardiomyocytes caused by OGD. The protein and mRNA expression levels of AQP1 were detected in rat cardiomyocytes, and were significantly increased in cardiomyocytes in the OGD/R group compared with those in the OGD group, which demonstrates that PEDF has no significant effects on the protein or mRNA levels of AQP1 in cardiomyocytes undergoing OGD. PEDF reduced AQP1 protein content and thus downregulated cardiomyocyte edema in the OGD/R period. The addition of the AQP1 agonist, AVP, inhibited the effects of PEDF on cardiomyocyte edema during OGD/R. As PEDF also decreased the mRNA level of AQP1, it was hypothesized that $P E D F$ reduces the protein expression of AQP1 by inhibiting AQP1 transcription. Previous studies have demonstrated that the protein and mRNA expression of AQP1 may be downregulated by microRNA (miR)-214 in the ischemic heart (33). Future investigations aim to determine whether PEDF mediates the decreased protein and mRNA levels of APQ1 via miRNA-214 and to examine the association between PEDF and miR-214. Further investigations are required to elucidate the mechanism.

A limitation of the present study was the restriction of the experiments, as the effects of PEDF on cardiomyocyte edema during OGD/R were only investigated in the cells and interstitial space. In addition, although it was determined that PEDF protected cardiomyocytes against edema when they underwent $15 \mathrm{~min}-2 \mathrm{~h}$ of OGD and $30 \mathrm{~min}-12 \mathrm{~h}$ of recovery, longer durations of OGD and recovery were been investigated.

In conclusion, the present study revealed that PEDF protects cardiomyocytes during OGD/R (I/R) via decreasing lactate accumulation and the expression of AQP1, respectively. These data presents a novel mechanism by which PEDF inhibits cardiomyocyte edema during OGD/R. The effect of PEDF on cellular edema may contribute to maintaining cell viability and improve the prognosis of patients with myocardial infarctions.

\section{Acknowledgements}

The authors would like to express thanks to Dr Tianyun Wang (Laboratory of Pharmacology, Xuzhou Medical University) for the HPLC analysis.

\section{Funding}

The present study was supported by a grant from National Nature Science Foundation of China (grant no. 81570242) and 
the Natural Science Foundation of Jiangsu Province (grant no. BK20150207).

\section{Availability of data and materials}

The authors declare that the materials described in the manuscript, including all relevant raw data, are freely available to any scientist wishing to use them for non-commercial purposes, without breaching participant confidentiality.

\section{Authors' contributions}

BH, HM, FQ, HD and ZZ conceived and designed the experiments. BH, HM, YY, ZL, XL, HZ, QZ and MW performed the experiments. BH, HM, HD and $\mathrm{ZZ}$ analyzed the data. $\mathrm{BH}$, HM, FQ and YY acquired the reagents, materials and tools for analysis. $\mathrm{BH}$ and $\mathrm{HM}$ produced the manuscript.

\section{Ethics approval and consent to participate}

The experiments described here conform to the Guide for the Care and Use of Laboratory Animals published by the National Institutes of Health (34). All animal care and experimental protocols were approved by the Animal Care and Use Committee of Xuzhou Medical University (license no. SYXK 2002-0038; Jiangsu, China) and international guidelines (European Council Directive 2010/63/EU) on the ethical use of animals (35).

\section{Patient consent for publication}

Not applicable.

\section{Competing interests}

The authors declare that they have no competing interests.

\section{References}

1. Garcia-Dorado D and Oliveras J: Myocardial oedema: A preventable cause of reperfusion injury? Cardiovasc Res 27: 1555-1563, 1993.

2. Basuk WL, Reimer KA and Jennings RB: Effect of repetitive brief episodes of ischemia on cell volume, electrolytes and ultrastructure. J Am College Cardiol 8 (1 Suppl A): 33A-41A, 1986.

3. Bragadeesh T, Jayaweera AR, Pascotto M, Micari A, Le DE Kramer CM, Epstein FH and Kaul S: Post-ischaemic myocardial dysfunction (stunning) results from myofibrillar oedema. Heart 94: 166-171, 2008.

4. Garcia-Dorado D, Oliveras J, Gili J, Sanz E, Pérez-Villa F, Barrabés J, Carreras MJ, Solares J and Soler-Soler J: Analysis of myocardial oedema by magnetic resonance imaging early after coronary artery occlusion with or without reperfusion. Cardiovasc Res 27: 1462-1469, 1993.

5. Butler TL, Egan JR, Graf FG, Au CG, McMahon AC, North KN and Winlaw DS: Dysfunction induced by ischemia versus edema: Does edema matter? J Thoracic Cardiovasc Surg 138: 141-147, 147 e141, 2009.

6. Sanz E, Garcia Dorado D, Oliveras J, Barrabés JA, Gonzalez MA, Ruiz-Meana M, Solares J, Carreras MJ, García-Lafuente A and Desco M: Dissociation between anti-infarct effect and anti-edema effect of ischemic preconditioning. Am J Physiol 268: H233-H241, 1995.

7. Friedrich MG, Abdel-Aty H, Taylor A, Schulz-Menger J, Messroghli D and Dietz R: The salvaged area at risk in reperfused acute myocardial infarction as visualized by cardiovascular magnetic resonance. J Am Coll Cardiol 51: 1581-1587, 2008.
8. Fernandez-Jimenez R, Sanchez-Gonzalez J, Aguero J, García-Prieto J, López-Martín GJ, García-Ruiz JM, Molina-Iracheta A, Rosselló X, Fernández-Friera L, Pizarro G, et al: Myocardial edema after ischemia/reperfusion is not stable and follows a bimodal pattern: Imaging and histological tissue characterization. J Am Coll Cardiol 65: 315-323, 2015.

9. Leaf A: Maintenance of concentration gradients and regulation of cell volume. Ann NY Acad Sci 72: 396-404, 1959.

10. Vandenberg JI, Rees SA, Wright AR and Powell T: Cell swelling and ion transport pathways in cardiac myocytes. Cardiovasc Res 32: 85-97, 1996.

11. Inserte J, Garcia-Dorado D, Ruiz-Meana M, Solares J and Soler J: The role of $\mathrm{Na}+\mathrm{H}+$ exchange occurring during hypoxia in the genesis of reoxygenation-induced myocardial oedema. J Mol Cell Cardiol 29: 1167-1175, 1997.

12. Butler TL, Au CG, Yang B, Egan JR, Tan YM, Hardeman EC, North KN, Verkman AS and Winlaw DS: Cardiac aquaporin expression in humans, rats, and mice. Am J Physiol Heart Circ Physiol 291: H705-H713, 2006.

13. Kruse E, Uehlein $\mathrm{N}$ and Kaldenhoff R: The aquaporins. Genome Biol 7: 206, 2006.

14. Manley GT, Fujimura M, Ma T, Noshita N, Filiz F, Bollen AW, Chan P and Verkman AS: Aquaporin-4 deletion in mice reduces brain edema after acute water intoxication and ischemic stroke. Nat Med 6: 159-163, 2000.

15. Page E, Winterfield J, Goings G, Bastawrous A and Upshaw-Earley J: Water channel proteins in rat cardiac myocyte caveolae: Osmolarity-dependent reversible internalization. Am J Physiol 274: H1988-H2000, 1998.

16. He X, Cheng R, Benyajati S and Ma JX: PEDF and its roles in physiological and pathological conditions: Implication in diabetic and hypoxia-induced angiogenic diseases. Clin Sci (Lond) 128: 805-823, 2015.

17. Gao X, Zhang H, Zhuang W, Yuan G, Sun T, Jiang X, Zhou Z, Yuan $H$, Zhang $Z$ and Dong H: PEDF and PEDF-derived peptide $44 \mathrm{mer}$ protect cardiomyocytes against hypoxia-induced apoptosis and necroptosis via anti-oxidative effect. Sci Rep 4: 5637, 2014.

18. Zhao Q, Liu Z, Huang B, Yuan Y, Liu X, Zhang H, Qiu F, Zhang Y, Li Y, Miao H, et al: PEDF improves cardiac function in rats subjected to myocardial ischemia/reperfusion injury by inhibiting ROS generation via PEDFR. Int J Mol Med 41: 3243-3252, 2018.

19. Qiu F, Zhang H, Yuan Y, Liu Z, Huang B, Miao H, Liu X, Zhao Q, Zhang H, Dong $\mathrm{H}$ and Zhang Z: A decrease of ATP production steered by PEDF in cardiomyocytes with oxygen-glucose deprivation is associated with an AMPK-dependent degradation pathway. Int J Cardiol 257: 262-271, 2018.

20. Zhang H, Hui H, Li Z, Pan J, Jiang X, Wei T, Cui H, Li L, Yuan X, Sun T, et al: Pigment epithelium-derived factor attenuates myocardial fibrosis via inhibiting endothelial-to-mesenchymal transition in rats with acute myocardial infarction. Sci Rep 7: 41932, 2017.

21. Lu P, Zhang YQ, Zhang H, Li YF, Wang XY, Xu H, Liu ZW, Li L, Dong HY and Zhang ZM: Pigment epithelium-derived factor (PEDF) improves ischemic cardiac functional reserve through decreasing hypoxic cardiomyocyte contractility through PEDF receptor (PEDF-R). J Am Heart Assoc 5: e003179, 2016.

22. Zhang H, Wang Z, Feng SJ, Xu L, Shi HX, Chen LL, Yuan GD, Yan W, Zhuang W, Zhang YQ, et al: PEDF improves cardiac function in rats with acute myocardial infarction via inhibiting vascular permeability and cardiomyocyte apoptosis. Int J Mol Sci 16: 5618-5634, 2015.

23. Maczewski M and Mackiewicz U: Effect of metoprolol and ivabradine on left ventricular remodelling and $\mathrm{Ca} 2+$ handling in the post-infarction rat heart. Cardiovasc Res 79: 42-51, 2008.

24. Sun M, Ouzounian M, de Couto G, Chen M, Yan R, Fukuoka M, Li G, Moon M, Liu Y, Gramolini A, et al: Cathepsin-L ameliorates cardiac hypertrophy through activation of the autophagy-lysosomal dependent protein processing pathways. J Am Heart Assoc 2: e000191, 2013.

25. Hao J, Li WW, Du H, Zhao ZF, Liu F, Lu JC, Yang XC and Cui W: Role of vitamin $\mathrm{C}$ in cardioprotection of ischemia/reperfusion injury by activation of mitochondrial KATP channel. Chem Pharm Bull (Tokyo) 64: 548-557, 2016.

26. Henry P, Popescu A, Puceat M, Hinescu ME and Escande D: Acute simulated ischaemia produces both inhibition and activation of $\mathrm{K}+$ currents in isolated ventricular myocytes. Cardiovasc Res 32: 930-939, 1996. 
27. Livak KJ and Schmittgen TD: Analysis of relative gene expression data using real-time quantitative PCR and the 2(-Delta Delta C(T)) method. Methods 25: 402-408, 2001.

28. Camilion de Hurtado MC, Portiansky EL, Perez NG, Rebolledo OR and Cingolani HE: Regression of cardiomyocyte hypertrophy in SHR following chronic inhibition of the $\mathrm{Na}(+) / \mathrm{H}(+)$ exchanger. Cardiovasc Res 53: 862-868, 2002.

29. Li XD, Yang YJ, Geng YJ, Cheng YT, Zhang HT, Zhao JL, Yuan JQ and Gao RL: The cardioprotection of simvastatin in reperfused swine hearts relates to the inhibition of myocardial edema by modulating aquaporins via the PKA pathway. Int J Cardiol 167: 2657-2666, 2013.

30. Porter AG and Janicke RU: Emerging roles of caspase-3 in apoptosis. Cell Death Differ 6: 99-104, 1999.

31. Zhang DW, Shao J, Lin J, Zhang N, Lu BJ, Lin SC, Dong MQ and Han J: RIP3, an energy metabolism regulator that switches TNF-induced cell death from apoptosis to necrosis. Science 325: 332-336, 2009

32. Frigeri A, Gropper MA, Umenishi F, Kawashima M, Brown D and Verkman AS: Localization of MIWC and GLIP water channel homologs in neuromuscular, epithelial and glandular tissues. J Cell Sci 108: 2993-3002, 1995.
33. Rutkovskiy A, Bliksoen M, Hillestad V, Amin M, Czibik G, Valen G, Vaage J, Amiry-Moghaddam M and Stensløkken KO: Aquaporin-1 in cardiac endothelial cells is downregulated in ischemia, hypoxia and cardioplegia. J Mol Cell Cardiol 56: 22-33, 2013.

34. National Research Council (US) Committee for the Update of the Guide for the Care and Use of Laboratory Animals: Guide for the Care and Use of Laboratory Animals. National Academies Press, Washington, DC, p220, 2011.

35. European Commission: Directive 2010/63/EU of the European Parliament and of the council of 22 September 2010 on the protection of animals used for scientific purposes. Off $\mathrm{J}$ Eur Union L276: 33-79, 2010.

(i) (9) This work is licensed under a Creative Common Attribution-NonCommercial-NoDerivatives 4.0 International (CC BY-NC-ND 4.0) License. 